\title{
Character Strengths Among Youth
}

\author{
Tracy A. Steen, ${ }^{1}$ Lauren V. Kachorek, ${ }^{1}$ and Christopher Peterson ${ }^{2}$
}

\begin{abstract}
Accepted April 11, 2002
Four hundred and fiftynine students from 20 different high school classrooms in Michigan participated in focus group discussions about the character strengths included in the Values in Action Classification. Students were interested in the subject of good character and able to discuss with candor and sophistication instances of each strength. They were especially drawn to the positive traits of leadership, practical intelligence, wisdom, social intelligence, love of learning, spirituality, and the capacity to love and be loved. Students believed that strengths were largely acquired rather than innate and that these strengths developed through ongoing life experience as opposed to formal instruction. They cited an almost complete lack of contemporary role models exemplifying different strengths of character. Implications of these findings for the quantitative assessment of positive traits were discussed, as were implications for designing character education programs for adolescents. We suggest that peers can be an especially important force in encouraging the development and display of good character among youth.
\end{abstract}

KEY WORDS: character; youth; high school; focus groups.

\section{INTRODUCTION}

In recent years, unprecedented strides have been made in understanding, treating, and preventing psychological disorders. Reflecting this progress and critically helping to bring it about are widely accepted classification manuals- the Diagnostic and Statistical Manual of Mental Disorders (DSM) sponsored by the American Psychiatric Association (1994) and the International Classification of Diseases (ICD) sponsored by the World Health Organization (1990) — which have given rise to a family of reliable assessment strategies and effective treatments for more than a dozen disorders that only a few decades ago were frighteningly intractable (Nathan and Gorman, 1998; Seligman, 1994). Lagging behind but still impressive in

\footnotetext{
${ }^{1}$ Doctoral Candidate, Clinical Psychology, Department of Psychology, University of Michigan, Ann Arbor, Michigan. Has research interests in positive psychology, especially the identification and measurement of positive traits.

${ }^{2}$ Arthur F. Thurnau Professor, Department of Psychology, University of Michigan, Ann Arbor, Michigan. Has research interests in positive psychology, especially the identification and measurement of positive traits. To whom correspondence should be addressed at Department of Psychology, University of Michigan, 525 East University, Ann Arbor, Michigan 48109-1109; e-mail: chrispet@umich.edu.
}

their early success are ongoing efforts to devise interventions that prevent disorders from occurring in the first place (e.g., Greenberg et al., 1999).

Consensual classifications and associated approaches to assessment provide a common vocabulary for basic researchers and clinicians, allowing communication within and across these groups of professionals as well as the general public. With recent incarnations of DSM and ICD, we can now describe and measure much of what is wrong with people, but what about those things that are right? Nothing comparable to DSM or ICD exists for the good life. When psychiatrists and psychologists talk about mental health, wellness, or well-being, they mean little more than the absence of disease, distress, and disorder (Jahoda, 1958). It is as if falling short of diagnostic criteria should be the goal for which we all should strive.

\section{The VIA Classification of Strengths}

One can curse the darkness or light a candle. We are currently creating a vision of what one candle reveals. Our project—dubbed the VIA (Values in Action) Classification of Strengths-means to complete what 
$D S M$ and ICD have begun by focusing on what is right about people and specifically about the strengths of character that make the good life possible (Peterson and Seligman, manuscript in preparation). We are following the example of DSM and ICD and their collateral creations by proposing a classification scheme and by devising assessments for its entries. The crucial difference is that the domain of concern to us is not psychological illness but rather psychological health. In short, our goal is "a handbook of the sanities" (Easterbrook, 2001, p. 23).

We write from the perspective of the fledgling field of positive psychology, which means that we are as focused on strength as weakness, as interested in building the best things in life as repairing the worst, and as concerned with fulfilling the lives of healthy people as healing the wounds of the distressed (Seligman, 2002). The past concern of psychology with human problems is of course understandable and will not be abandoned anytime in the foreseeable future. Problems that demand psychological solutions will always exist, but psychologists interested in promoting human potential need to pose different questions from their predecessors who assumed a disease model of human nature. We self-consciously disavow the disease model as we approach character, and we are adamant that human strengths are not secondary, derivative, illusory, epiphenomenal, or otherwise suspect. Said in a positive way, we believe that character strengths are the bedrock of the human condition and that strengthcongruent activity comprises the psychological good life.

There are many good examples of psychological research, past and present, that fit under the positive psychology umbrella, but this new field lacks a common vocabulary for moving among these instances. We imagine that positive psychology as a whole would be benefitedindeed, shaped and transformed - by agreed upon ways for speaking about the positive, just as DSM and ICD have shaped psychiatry, clinical psychology, and social work by providing a way to speak about the negative. We believe that the classification of character we intend is an important step toward a common vocabulary, specifically one that allows us to speak about positive traits.

\section{Positive Psychology and Youth Development}

The purpose of this paper is to describe our initial steps to apply our classification to a specific population: adolescents in the contemporary United States. Positive psychology as a field has emerged in parallel with changes in the way the interdisciplinary field of youth development has approached its goal of "developing" young people
(Larson, 2000). Youth development has always had a strong interest in application (Catalano et al., 1999). Throughout much of the 20th century, these applications were directed at youth problems like school dropout, juvenile crime, alcohol and drug use, and unwanted pregnancy. The earliest interventions targeted young people in crisis-i.e., helping youth with problems - whereas the more recent interventions have been preventive-i.e., supporting youth before problems develop.

Another change occurring as the field of youth development has matured is that prevention efforts targeting but a single problem have come under criticism. Many problems co-occur and have the same risk factors. Broadbased interventions can therefore have broad effects. Part of the broadening of youth development and its applications has been a call for studying and eventually cultivating what has come to be known as positive youth development-desirable outcomes such as school achievement, vocational aspirations, community involvement, good interpersonal relations, and the like. As Pittman (1991, 2000) phrased this change, "problem-free is not fully prepared." Here is where youth development converges with positive psychology and its premise that the best in life is not simply the absence of disorder and dysfunction.

Some youth development proponents seem to be ambivalent about the notion of character, perhaps because of its objectionable implication that the kids would be okay if they only learned to say no. Needless to say, a concern with character does not preclude acknowledging the role played by external systems in shaping the person, for better or for worse. But if youth are to be developed, we need to say just what it is about them that develops. We suggest that one answer is their character, construed in terms of positive traits.

As an applied field, youth development marches to the drummer of societal priorities, and the reduction of problems among youth has been the priority, for good reasons. "Positive" outcomes can be a difficult sell when juxtaposed with tax cuts, pothole repairs, airport security, and defense spending, But there is good reason to believe that attention to positive outcomes has the additional effect of reducing negative outcomes. Researchers at the Search Institute in Minneapolis have studied what they call developmental assets, which include external factors like family support and adult role models and internal factors like commitment to learning, positive values, and sense of purpose (Benson et al., 1998; Leffert et al., 1998; Scales et al., 2000). Youth with more of these assets not only show fewer problems but also display more evidence of thriving (e.g., school success, leadership, helping others, and physical health). The internal assets of interest to these 
Table I. The VIA Classification of Strengths (Peterson and Seligman, Manuscript in Preparation)

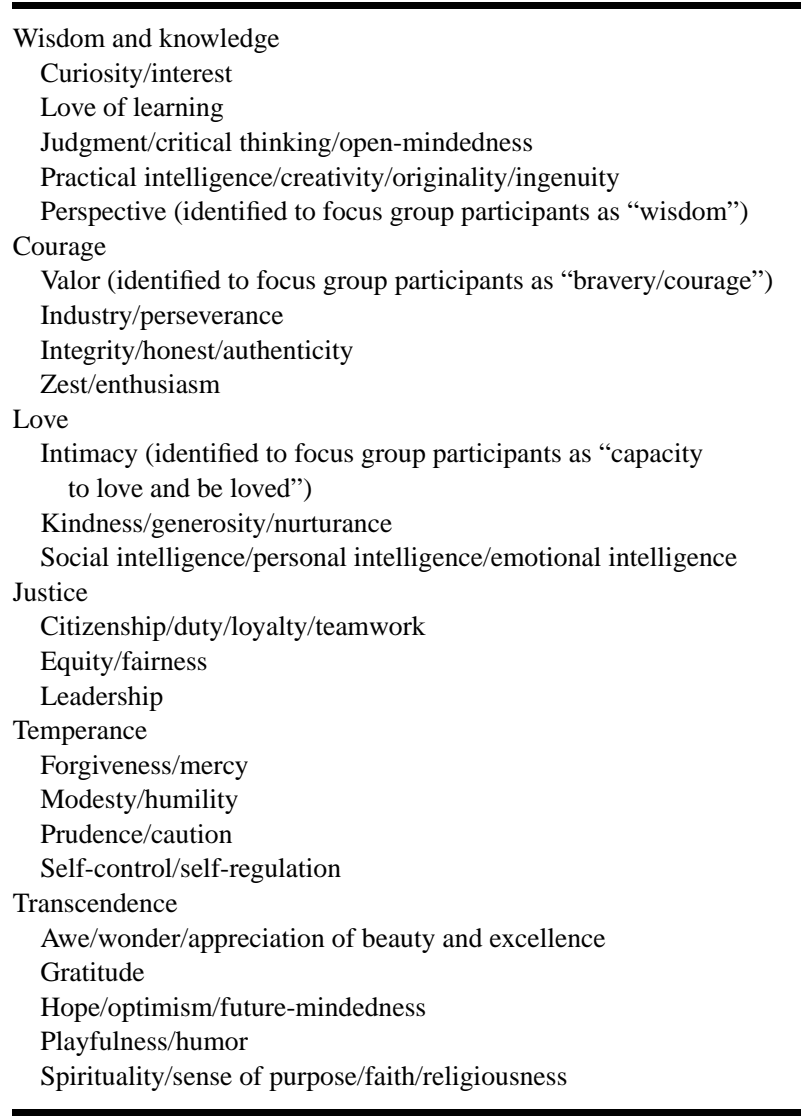

researchers correspond to the sorts of character strengths with which we are concerned.

This article is not the appropriate forum to detail the thinking that has led up to the specifics of the VIA Classification (see Table I). Suffice it to say that the classification specifies 24 ubiquitously valued strengths of character organized under 6 broad virtues that represent a consensus of how major philosophical and religious traditions over the centuries have answered the question "What is the good of a person?" (Dahlsgaard et al., 2001). The stance we take toward character is in the spirit of personality psychology, and specifically that of trait theory, but not the caricature of trait theory so unfairly held up as a straw man and then criticized by social learning theorists in the 1970s. We rely instead on the "new" psychology of traits that recognizes individual differences that are stable and general but also shaped by the individual's setting and thus capable of change. We have unpacked character, by specifying its components, by being concerned with measurable behavior (thoughts, feelings, and actions), by viewing these components as dimensions rather than categories, and by situating them in the immediate social environment as well as the larger streams of society, culture, and history (Peterson and Seligman, manuscript in preparation).

\section{The Present Study}

What distinguishes the VIA Classification from most previous attempts to articulate good character is its simultaneous concern with assessment. How can we measure a person's strengths? Sophisticated social scientists sometimes respond with suspicion when they hear our goal, reminding us of the pitfalls of self-report and the validity threat posed by "social desirability" (Crowne and Marlowe, 1964). We do not dismiss these problems out of hand, but their premise is worth examining from the vantage of positive psychology. We seem to be quite willing, as researchers and practitioners, to trust what individuals say about their problems. With notable exceptions like substance abuse and eating disorders, in which denial is part and parcel of the problem, the preferred way to measure psychological disorder relies on self-report, either in the form of symptom questionnaires or structured interviews. So why not ascertain wellness in the same way? Perhaps we accept self-reports about the negative but not the positive because we do not believe that the positive really exists. That is the pervasive assumption that positive psychology urges us to reject.

Suppose for a moment that people really do possess moral virtues. Most philosophers emphasize that virtuous activity involves choosing virtue in light of a justifiable life plan (Yearley, 1990). In more psychological language, this characterization means that people can reflect on their own virtues and talk about them to others. They may of course be mistaken, but virtues are not the sort of entities that are in principle outside of awareness or the realm of self-commentary (cf. Nisbett and Wilson, 1977). Furthermore, character strengths are not contaminated by a response set of social desirability; they are socially desirable, especially when reported with fidelity.

We can point to previous research that measured character strengths with self-report questionnaires (e.g., Cawley et al., 2000; Greenberger et al., 1975; Ryff and Singer, 1996). In no case did a single "methods" factor order the data. Rather, different clusters of strengths always emerged. External correlates were sensible. These conclusions converge with what we have learned to date from our own attempt to measure the VIA strengths among adults with a self-report questionnaire (interested readers can complete the current version of the questionnaire at http://positivepsychology.org/strengths). We admit that some strengths of character lend themselves less readily to 
self-report than do others, but it is easy to understand why. Almost by definition, strengths like authenticity, modesty, and valor are not the sorts of traits often attributed to oneself. But this consideration does not preclude the use of self-report to assess other strengths of character.

The impetus for the present study was our goal of devising an assessment strategy suitable for young people. Our preliminary work on the VIA Classification focused on adults, and we did not want simply to age regress our ideas and measures. Character strengths show a developmental trajectory, and some "adult" strengths may not have strict counterparts among younger individuals; perspective is an obvious example of a strength that no doubt has adolescent precursors but perhaps not an adolescent manifestation. Furthermore, character strengths exist in a sociocultural ethos that may vary considerably across groups of people, including generational cohorts. It is unknown without empirical investigation whether the ways that young people display and recognize character strengths are comparable to the ways of older people.

Accordingly, we conducted a number of focus groups with high school youth in which we talked to groups of adolescents about character and character strengths. We followed a common format guided by these questions: (a) Does the basic idea of a character strength make sense to youth; (b) How do young people define and recognize instances of the different strengths in the VIA Classification; (c) Do individual adolescents "own" certain strengths; that is, can they readily claim specific strengths as their own while disavowing others; and (d) How do youth view the origins and development of these strengths across the lifespan?

\section{METHOD}

In January 2001, superintendents of 15 high schools in the state of Michigan were contacted by phone or letter inviting the participation of their schools in this project. Five schools comprised the final sample: Pioneer High (Ann Arbor Consolidated Schools), Manchester High (Washtenaw Schools), Milan High (Milan District), and North Farmington High and Harrison High (Farmington Schools). Superintendents provided the names of teachers whose classes could serve as the focus groups, and these teachers were then contacted directly by phone or e-mail. Cooperating teachers distributed assent forms to their students and consent forms to the parents of the students. Only 1 student failed to return a parental consent form, and he therefore did not participate in a focus group.

Twenty different classes served as focus groups, totaling 459 students. Subject matter of the classes ranged from English to psychology to Spanish. Students from 9th through 12th grades were represented, ranging in age from 14 to 19 ( $x=16$ years). The students were $52 \%$ female, $80 \%$ white, and mainly middle class.

Between March and May, 2001, focus groups were conducted during a single session of regular class time, from 45 to $90 \mathrm{~min}$, and were led by 1 or 2 female graduate students in clinical psychology (TAS and LVK). The teacher was usually present in the room but did not actively participate. The focus group leader(s) briefly introduced the discussion by explaining the goal and procedure of the present project: to understand through group discussion what adolescents think about character strengths. Students were told that the focus group leader(s) would periodically ask questions, but more important was what the students themselves thought about character strengths. They were instructed not to ponder how others might want them to respond but to answer honestly and spontaneously. Students were asked to contribute to the discussion by jumping in whenever they had an opinion to express. All discussions were audiotaped and later transcribed.

The researchers nonsystemically chose 4-6 specific character strengths for discussion by each class. Most of the VIA character strengths were discussed by at least 3 different classes. To guide the discussions, the group leader(s) asked the following for each character strength under discussion:

- Would someone give an example of people they know or have heard about who are particularly What are they like? How do you know that they possess ? Give an example of when someone showed a lot of

- Would anyone be willing to share an example of a time in your own life when you needed to be (or have) --_-_-_--_?

- What makes it hard to be of things keep people from showing sometimes?

- Are there any particular situations in which it is particularly important to be ?

- How do people become ? (Probe to explore whether students believe that trait is innate vs. learned. If students believe it is learned, explore where they believe it is learned.)

- Let's come up with a definition of what it means to be _-_. If someone did not know what it meant to be _-_ what this means?

Although we used these questions as a guide, time usually permitted us to allow students to explore topics that were related to the general subject of human character strengths as they surfaced in the discussion. 
In the VIA Classification, we deliberately used different labels for the 6 broad virtue classes and the 24 specific character strengths (see again Table I). To avoid confusing the students, in a few cases we described the specific strengths with labels assigned to the virtue classes. As Table I shows, we identified the VIA strength perspective as "wisdom," the VIA strength valor as "bravery/courage," and the VIA strength intimacy as "capacity to love and be loved." In all cases, we introduced a character strength for discussion by using all of its synonyms as shown in Table I.

Ten minutes were reserved at the end of each class period so that students could ask the discussion leaders any questions that might have arisen during the session. Leaders then thanked teachers and students for their willingness to contribute and promised to provide a summary so that they could see how students' ideas compared and contrasted with those of their peers in others classes and other school districts.

\section{RESULTS AND DISCUSSION}

The overall conclusions reported here apply to each of the 20 focus groups, implying good generality. We begin this discussion of our results with some general observations about the exercise and how young people conceive character. Then we discuss findings with respect to several specific character strengths. Space does not permit a discussion of all the VIA strengths, so we have selected those that illustrate more general points.

\section{Group Dynamics}

Approximately $95 \%$ of students who returned assent and consent forms actively participated in the focus group discussions. They appeared to enjoy the attention and the fact that their ideas were being solicited and valued. Students were overheard describing the groups as fun or cool, and a number of students stated that they welcomed the change from their usual classroom activities. Some students contributed more than others, but in no group did 1 or 2 students dominate discussion. A student's inclination to participate did not appear to be a function of gender or ethnicity, nor did a student's typical level of involvement in classes (as reported to us by the teachers) appear to be a factor. On numerous occasions, students and teachers noted that students who were rarely vocal in class were particularly active in the focus group. At the end of one session, for example, a female student made the following comment to a male student who had made numerous thoughtful contributions to the discussion:

Wow, this was a good day for you! I guess you've just been hanging back all year, taking it all in and just waiting for your day to shine.

Students appeared comfortable voicing their opinions in front of their peers. Numerous participants volunteered examples from their own lives in which they wished they had displayed more of a particular character trait. The students themselves did much to contribute to a comfortable environment. Overall, they were respectful of one another's opinions. Although it was not uncommongiven the instructions-for students to interrupt others while they were speaking, these exchanges typically had a friendly, back-and-forth quality to them. It appeared as though students were using one another to work through challenging concepts.

The following interaction took place among 3 students who were attempting to agree on a definition of a good leader. Prior to this exchange, female student 1 stated that she considered Michael Jordan a good leader. Male student 1 voiced his disagreement, explaining that Michael Jordan was more of a role model than a leader. Female student 2 also entered the discussion.

Female Student 1: Well, I think if you are a leader you are also a role model, and I think if you're a role model you are a leader. I don't think there is really a firm definition [sic] between the two. I mean, what does a leader do that a role model doesn't do?

Female Student 2: Leaders want to change things and make things better.

Male Student 1: Yeah, and when I was in Boy Scouts, my scoutmaster was a leader, but I didn't consider him a role model. I did not want to be like him, necessarily, but he did make me want to do the things he was trying to teach me. So I think there's definitely a difference between being a good leader and being a role model.

Female Student 1: Yeah, I see what you mean. Like I consider President Clinton to be a good leader but not a role model. And I consider President Bush to be a good role model but not a great leader.

This exchange was typical of the dialogues we observed. Students challenged one another to think deeply and support their ideas, and they typically did so in a respectful manner. Students seemed to pride themselves on being nonjudgmental and accepting of opinions different from their own. It was common for students to preface their comments by acknowledging that "This might not be true of everyone" or "Other people might see this differently." 


\section{General Beliefs About Good Character}

As group discussions unfolded, it became clear that students conceptualized the strengths as existing along continua, with people exhibiting different traits to varying degrees. Although students believed that some people naturally possess more or less of a given strength, they also believed that all of them could be learned or developed. A female student typified this view during a discussion of courage:

\footnotetext{
I think some people are naturally more courageous than others. But I also think you can, like, learn to be courageous. Like if you start out afraid of snakes but then you are forced to be around snakes all the time, then you might learn to be less afraid.
}

If students believe that character traits can be learned, from what source (or from whom) do they think the traits are acquired? Life experience was by far the most frequently cited source of character. A female student described how she developed her social intelligence by interacting with individuals from different backgrounds:

\begin{abstract}
This past February I went down to Detroit to work in a food shelter. When I first got down there I felt really uncomfortable because I had never been in an inner city and I had never spoken to a lot of poor, underclass African-Americans or even people of different ethnicities or races ... But after I just kept talking to everyone, I felt more comfortable... So by the end of the day I didn't feel like a pro or anything, but I was socially smarter.
\end{abstract}

Other students discussing social intelligence specified that this trait is most easily acquired through real life experiences "away from home" and "without your parents." However, some students also suggested that you could acquire social intelligence and other traits vicariously through watching "lots and lots of TV." Our discussion did not encompass views on how television might promote or thwart the development of specific character traits among adolescents, but this would be an interesting area for future inquiry. For example, does the Discovery Channel promote curiosity or love of learning? Do the outrageously daring escapades in action thrillers subtly denigrate the strength of prudence?

Most adolescents felt that the strengths could be fostered by deliberately "working at them" but that this was not nearly as important a source of character as ongoing life experience and the lessons gleaned from it. A number of participants named hardship as a particular type of life experience that could engender character strengths. One male student talked about how he was better able to appreciate beauty in the world- to stop and smell the roses-after surviving a terrible car accident. Another male student cited a similar experience, relating how he became more zestful and enthusiastic about life following his accident. Similarly, a female student told a moving story about a friend who learned to appreciate beauty in the world after a scary period during which she thought she might have contracted HIV: "She doesn't take anything for granted now."

Students credited school with the formation of character only to the extent that school was a place where they might acquire general life experience through interactions with their peers. One male summarized the position taken by the majority of the students: "You can learn a lot of these things [character traits] while you are at school, but usually not when you are in class." In fact, many students stated that school actually hindered the development of certain character strengths. It was not uncommon for students to state that they used to be really curious or that they used to love learning but that the tedium of classroom activities had caused these traits to atrophy.

As we have stressed, students considered life experience to be integral to the formation of character. But interestingly, they did not take the position that more life experience necessarily translates into better character. In a discussion of wisdom, for example, students suggested that wisdom does not always come with age and increased experience. One female student made the following comment:

\footnotetext{
Some of the wisest people I know are in high school, but their opinions are not valued as much because they are seen as just teenagers rather than people who have really, really good ideas. Like I know some people in high school that I would rather elect president than our current president.
}

We speculate that popular media may contribute to the belief by adolescents that wisdom does not accompany maturity. Coming-of-age movies, presumably popular with youth, invariably caricature adults as pompous and foolishly narrow-minded.

Students also frequently cited the influence of parents on the development of character. Interestingly, however, many students expressed the opinion that parents could shape the development of character for better or for worse. In a discussion of what it means to have the capacity to love and be loved, a male student stated:

\footnotetext{
People learn to love from their parents. Kids have it hard when they grow up in a home with parents who don't show any love to the kids or to one another. The kids grow up and they don't know how to relate to other people right.
}

Similarly, during a discussion of what it means to be a good leader, students suggested that parents can encourage the development of this trait by teaching their children to 
"stand up for themselves" and to be "open-minded," but they also have the power to squelch the development of good leadership skills:

Some parents tell their kids to never talk out loud... Or maybe their parents will tell them that if they disagree, then they might get slapped or hit. That would teach them to just go with the flow and never take a stand.

Although students provided numerous examples of how parents might hinder the development of character traits, they did not see this influence as final. As one male student explained:

Parents try to bring you up just like them so that you believe the same things are right and wrong as they do. But when you get to a certain age, you start to decide these things for yourself.

Furthermore, some students voiced the opinion that they have developed positive character traits in reaction to what their parents were modeling. During the a discussion of humility, a male student stated the following:

Like every time I do something good in sports and I'm in the paper or something, my parents always brag to their friends . . . and I don't like it when they do that. I'm humble because I don't want to be like them.

Because individuating from parents is an important developmental task of adolescence in the contemporary United States, it follows that many students did not try to model themselves after their parents. But what was notable was the reported dearth of contemporary role modelsparental or otherwise-in their lives. When students were asked to give examples of individuals who exemplified the various strengths, they were more likely to name biblical figures or civil rights leaders from the 1960s rather than exemplars from contemporary society. When we asked students about their tendency to name individuals from past decades or centuries, they expressed a cynicism about what is valued in today's society. One male student observed:

We just don't see many people today who are wise or honest or whatever because those sorts of things aren't valued as much in our society. In our society, we don't care if you are wise or whatever. It's just if you can do your job well and get paid well. Then you're cool.

A female student expressed a similar sentiment:

I just don't think there are that many great leaders today. I mean, look at our presidents. They're supposed to be these great leaders and half of the world doesn't even like them. And you can look at leaders at the school level and see the same thing. I mean, I wouldn't call our administrators people who we would model ourselves after or anything.
I mean, I really can't think of a leader that I could say, oh, wow, I want to be like them.

One student took a slightly less cynical view and suggested that perhaps there are plenty of people out there with the potential to be great role models or leaders. But in recent years, we simply have had fewer opportunities for individuals to be heroes:

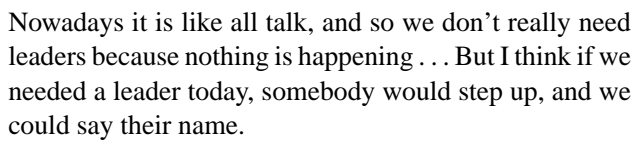
leaders because nothing is happening ... But I think if we needed a leader today, somebody would step up, and we could say their name.

In the aftermath of September 11, this state of affairs may change. Indeed, the media are deluging us with stories of everyday heroes; only time will tell if youth embrace as role models the individuals featured in these stories. Our worry, without denying the real virtues displayed by people rising to the occasion of September 11, is that 30-seconds sound bites do not have sufficient depth to influence adolescents to change their behavior.

\section{Particular Strengths}

We were impressed with the degree to which our high school students appreciated the complexities of the character traits under discussion. Students recognized that individual strengths are not acquired or used in isolation from one another. Many students attempted to explain how an individual's signature strengths functioned as a coherent package. Indeed, students recognized that the development of certain strengths depended on the existence of others. For instance, curiosity was seen as a prerequisite for love of learning, judgment as a prerequisite for self-regulation, and so on. Here is a reminder to positive psychology researchers not to study given strengths in isolation from the others.

In fact, students seemed to enjoy the process of examining closely related concepts and discussing subtle differences in meaning. For example, in our discussion of leadership, one group deemed it critical to make the distinction between being a good leader and being an effective leader. According to this group, good leaders have noble goals and care about the people they lead. In contrast, effective leaders get things done, but they might not necessarily be advancing noble causes. These students agreed that Adolph Hitler was an example of an effective leader but not a good leader.

Similarly, during a particularly animated discussion of practical intelligence, one group talked at length about the difference between street smarts and common sense. One male student who had remained silent for much of 
the discussion volunteered the following:

Street smarts is more something that varies with society ... Like 100 years ago it would have been totally different how to react in a bad neighborhood than it is now. Like someone who was really street smart 100 years ago would be like totally screwed in like Brooklyn. But common sense... It's like knowing not to put your hand in the fire. It doesn't change.

Another student nodded enthusiastically and added:

Yeah, common sense is like mojo [charm, luck, magic]. It's the ability to just do things right without really even having to think about them. Like the ability to just make the right choices.

During the discussion of wisdom, most groups commented that wisdom was more than just book smarts or possessing knowledge. Many students described wisdom as something "deeper" and less common than knowledge, which they tended to characterize as "superficial learning, like memorizing facts.” But one male student took a more psychological approach:

\begin{abstract}
Knowledge is more of a conscious thing that you learn, and wisdom is closer to the subconscious. Having wisdom affects you more deeply and changes who you are.
\end{abstract}

As already mentioned, it was somewhat surprising that few students associated wisdom with advancing age.

Students tended to view the capacity to love and be loved as a particularly complex trait. Most agreed that the capacity to love typically co-occurs with the capacity to be loved, though it is possible for someone to be loved without loving in return. And a number of students voiced their belief that in order to truly love someone else, "you have to love yourself first." (This sentiment is well established in pop culture, so the adolescents who offered it may have been giving a pat answer rather than conveying their personal thoughts on the matter. However, a popular aphorism can influence attitude, and its expression was thus pertinent to our group discussions.) It was common for participants to suggest that we need different words to describe the love that exists between relatives and the love that exists between romantic partners. Some students even mentioned agape or "God's love." At the end of one discussion in which participants listed all the many different types of love, one female student sighed and said:

I don't know. I think all these different kinds of love are still about the same connection between people. Like I can be in love with my boyfriend or in love with my teachers... They are different forms, but the same root. It's all about affection. They're just expressed differently.

Traits such as those just discussed sparked rich discussion among the participants. And notably, students al- most without exception agreed that the traits they viewed as complex and worthy of extended discussion were also traits they strongly desired for themselves: leadership, practical intelligence, wisdom, and the capacity to love and be loved. This suggests that students are not turned off by strengths that are more abstract or by traits that are less commonly discussed in our society.

Other traits that resonated with the students included social intelligence, love of learning, and spirituality. Even high school students are aware that the ability to get along with others (having social intelligence) plays a large role in social and career success. A number of students stated that they were trying to develop their social intelligence. And many students viewed love of learning and spirituality as valuable traits that they already possessed. The majority of students considered themselves people who love to learn, although many were quick to add that this did not mean that they enjoyed school. Students cited the fact that they loved to watch educational television programming as evidence of their love of learning. Spending hours in bookstores just for the fun of it or enjoying travel were also commonly cited as evidence of this valued strength.

We found it interesting that the vast majority of students considered themselves spiritual. A number of students stated that a belief in the Christian God was part of their own spirituality. But just as many students suggested that although they were quite spiritual, they were not religious. Many participants expressed the belief that spirituality is something defined by the individual. As one student stated:

\footnotetext{
You can be spiritual and just believe in your connection to the earth and other people. It's just being aware of something beyond you and your own little world.
}

It is important to note that students did not view all character traits as ubiquitously good. There were some traits that students perceived as desirable only in moderation or in certain circumstances. And there were others that students did not seem to value much under any circumstances. The strength of prudence/caution stands out as particularly unappealing to most high school students. When this trait was introduced, it was often met with wrinkled noses and rolled eyes. A number of students were quick to voice their opinion that being cautious was more of a vice than a virtue. As one female student stated:

I think a lot of the time, cautious people get behind in life. They are too worried about making sure that everything is secure before they do anything.

A male student agreed, adding:

The only time to be really cautious is when you are in a situation where if you screw up one little thing, you die. 
In any other situation, it's okay if you screw it up because you'll learn from it.

It seems that for most students, caution/prudence is a stuffy trait associated with timidity and lack of adventurousness.

Students' views of curiosity and kindness were more mixed. Overall, students viewed these traits as desirable, yet their discussions of these particular traits were peppered with examples of how these traits could be bad or dangerous. For example, a male student suggested that curiosity might lead people to make bad decisions:

Like you could be curious about what certain drugs would be like. That happened to a friend of mine, and she got addicted.

Another student volunteered that suicide could be the result of curiosity about what exists after death. When citing these dangers, it apparently did not occur to students that the previously disparaged trait of prudence might temper excessive curiosity. Students also discussed a darker side of kindness. For most students, more is not necessarily better when it comes to kindness. One female student explained her view as follows:

I think there are people that are too kind and it gets them in trouble because people take advantage of them... And they're always willing to do stuff for others and go that extra mile, but then they can be so kind that they start to run themselves ragged... Or they might put themselves in bad situations where they're like tired and stressed out and then other bad things come.

Other students took this idea one step further by stating that kindness is particularly likely to become a less than desirable trait if people are not at least as kind to themselves as they are to other people. As one student explained:

Some people want to do good for everybody, but then they end up taking so much time out of their day that it affects their health or their well-being and they should really try to get more sleep and think about themselves.

As evidenced by the previous example, students did not prize acts of extreme selflessness, but they were also quick to condemn acts of extreme selfishness. For example, during a discussion of leadership, students were critical of the selfish means by which some effective leaders acquire their power. As one female student stated:

To get into leadership roles nowadays, you have to step on a lot of people. Like you can't get into the presidency without stepping on a lot of people and without money grubbing and all sorts of stuff.

\section{CONCLUSIONS}

In conceiving this project, we recognized that our goal depended on the cooperation of high school students who might be reluctant to take our task seriously or feel comfortable enough to speak freely in front of their peers. It seemed a real possibility that when we began talking about character, students would consider us out of touch with their realities. We feared that their response to our inquiries might be a blank stare or gaze avoidance, but this apprehension proved groundless. The students participated readily and openly, responding to our questions and debating the issues with one another.

Their discussions indicated that certain strengths were particularly valued among the students - traits such as leadership, practical intelligence, wisdom, social intelligence, love of learning, spirituality, and the capacity to love and be loved. But even though these traits garnered the most positive comments, the students were willing to address all strengths raised for discussion. We were impressed by their perseverance at confronting challenging concepts and with their sophistication in the dialogues that ensued. When given sufficient time to think and discuss, most students showed that were capable of understanding even the most abstract traits.

Thus, we take from this exercise the knowledge that not only are adolescents capable of understanding the character traits in the VIA classification but also that they consider their acquisition to be worthy. Their demonstrated capacity and attitude bode well for the recent trend in education to include character education programs, although caveats are of course in order (Otten, 2000). The success of these programs will be influenced importantly by the means chosen to introduce and examine the subject of good character. Most basically, the meaning of character education must be examined carefully and in some cases expanded beyond currently narrow interpretations. Rather than simply telling students what to do, character education programs need to help students learn how to make difficult ethical choices and decisions. Based on our discussions with the students in the study, we offer four general conclusions about suitable methods for teaching adolescents about character.

First, students place a premium on life experience as a means of building character. Their expressed preference for learning from experience suggests that experiential programs would be particularly effective for adolescents. When studying the character strength of equity/fairness, for example, students could visit a local court hearing (or watch a rerun of a famous court trial on television) and then discuss their ideas about the characteristics of a fair judge. Likewise, when discussing the character strength 
of kindness, students could be encouraged to engage in acts of kindness or generosity, recording in a journal the thoughts and feelings generated by the exercise. Because of their flexibility, after-school youth development programs would seem a particularly good way of providing character-building life experience. We note, however, that few of the students in our focus groups explicitly mentioned youth programs as a source of character, which means that these programs need to do a better job, if only by naming for participants what it is that they are trying to accomplish.

Second, the tendency of some character education programs to present character strengths in a "flavor of the week" format is at odds with the obvious sophistication that youth can bring to bear on the topic. As we have mentioned, adolescents recognize various strengths as interdependent, and character education programs must do the same if they are to be credible. Along these lines, innovative sex education programs now present more complex messages to students, simultaneously addressing abstinence and safer sex and relying on the good sense of young people to sort through what seem to be mixed messages (Kirby, 1997). Character education programs that focus on strengths should assume no less of their students.

Third, we emphasize students' evident hunger for contemporary role models. It seems that students would benefit greatly from being exposed to individuals in their community who exemplify a particular character trait in a noteworthy way. For example, students might learn about (and ideally meet) a young dot com CEO from their community who had the courage to start a business on her own and who demonstrated the perseverance and ingenuity necessary to enter and survive a tumultuous market. Or they might learn about kindness from volunteers in their local community's service organizations such as soup kitchens or hospices. They might learn about love from an individual caring for a spouse incapacitated with Alzheimer's disease. They might learn from firefighters how to balance courage and prudence. Aside from introducing the students to role models for the various character traits, these exposures would also employ to some extent the desirable aspects of experiential learning as previously discussed. Young people also have to learn to be wise enough to see that no one is perfect, even a paragon of a particular character strength. Part of introducing role models to youth would thus entail providing an intellectual context in which someone's virtues can be appreciated even as his or her flaws are acknowledged.

A fourth observation from our focus groups pertains to peer pressure. Although the powerful force of peers is widely acknowledged with respect to adolescents, it is generally considered a negative force. In contrast, the be- havior of participants in our focus groups suggests that peer influence can be a positive force in promoting specific character traits when those traits are considered and discussed within the peer group. When students learn from group discussion that their peers value certain character traits, they are likely to be influenced in their own thinking about those traits. If the students already have positive views about the trait in question, then their peers' remarks will simply affirm those positive opinions, possibly strengthening them. If, on the other hand, some of the students listening to a discussion have previously rejected, disparaged, or given little thought to the trait in question, their peers' opinions will perhaps change their minds. Although group dynamics will vary with the composition of the group and the skill of the facilitator, our experience with the various focus groups suggests a useful application. When a group consensus regarding a particular trait is positive, it is conceivable that the peer influence may have a greater impact among the group membersby forming or affirming or revising opinion-than could be achieved by more formal instruction. Research is obviously needed to compare various methods of promoting various character traits. In the meantime, perhaps schools could implement group discussions, similar to those facilitated in our focus groups, as part of their character development programs, thus employing peer influence to foster a positive attitude toward character strengths.

With the development of new character education programs in schools and youth organizations, the need for an effective means of evaluating these programs is clear. Our next step is to develop measures for assessing character strengths in adolescents, using the findings from the focus groups to inform the process. As we contemplate quantitative assessment, the overall candor we observed within the focus groups is encouraging. Students appeared to feel comfortable speaking about perceived character deficits as well as strengths in front of their peers, and we are hopeful that giving students the opportunity to assess their relative character strengths on a confidential written measure would only increase the accuracy of their assessments. The challenge will be to design measures that are both meaningful and relevant.

One way to assess character strengths among adolescents is of course with self-report questionnaires, but we need to be careful that the questions pertain to strengths that are developmentally salient. Another strategy is to have adolescents respond to short narratives in which the main character exemplifies a particular trait. After they read these vignettes, the students might be asked to report how likely they would be to act in a similar way and how much they agree with the behavior of the main character (i.e., the degree to which they value the exemplified trait). 
Based on our experience with the focus groups, we anticipate that most students will be capable of understanding each of the traits we have identified, provided that we use age-appropriate language and present the traits in behavioral terms (via the narratives). Whenever possible, we will derive the narratives from students' own examples, such as those generated by our focus groups, thus ensuring that the behavioral terms in the questionnaires are appropriate to adolescent experience.

As future research is conducted in this area, it will be critical to continue obtaining feedback from the adolescents for whom any interventions or measures are designed. The content of our focus groups revealed unmistakable cynicism when students spoke about traditional education. It is possible that the wrong approach to character development could stifle rather than encourage incipient student interest. Students in our focus groups indicated a willingness to be challenged and a desire to think for themselves. But they also expressed an appreciation for the fact that they were sharing opinions rather than receiving indoctrination. Recognizing the difference between the two and the aversion of adolescents to the latter appear crucial in securing the cooperation necessary for valid research and successful intervention. Fortunately for researchers and educators, the interest among students in human character strengths is already there. The challenge will be to ensure that student input continues to inform the creation of measures and interventions so that we do not inadvertently suppress their interest and make character uncool.

There is a role for some formal lessons about character and what it means. Despite our best efforts, a few of the labels we used for strengths initially confused the students. For example, some students thought humility entailed humiliation. Perhaps this conflation is merely a matter of vocabulary. A more serious challenge for character education is that even in this age of supposed gender-role equality, certain strengths were stereotyped as belonging to a particular gender. Notably, some male students said that emotional intelligence was something that "only women must think about."

Part of what teachers need to do is to draw attention to the conflicting moral messages inherent in the fabric of most schools. For example, students in a typical school are urged to be cooperative, yet individual achievement and competition may still result in the most rewards. Love of learning is held up as a virtue, but teachers and administrators may look the other way when a star athlete neglects his assignments. Character education programs should try to transform not just students but also schools so that nice guys do not have to finish last.
Finally, effective character education must take a positive focus. Adolescents are already bombarded with admonitions - Don't do drugs; Don't drop out; Don't get pregnant. The prevalence of so many warnings emphasizes the risks inherent in navigating our culture, and most adolescents are aware of the dangers. The pressures to ignore or succumb to the hazards are very real, particularly for those in high-risk circumstances like poverty or family dysfunction. When adolescents find dangers that they cannot control-in the external settings of their lives-there is reassurance in discovering that they can take charge of what is internal (Desetta and Wolin, 2000). They can exercise personal control that will make a difference in who and what they are. They can do more than simply avoid the hazards; they can seek to maximize their potential for living a good life. Our focus groups revealed that most students believe it is possible to develop character strengths, and this belief can foster purpose. When adolescents have the opportunity to examine the elements that comprise strong character, they may choose to develop themselves in a life-enhancing way, and thus shape their future as well.

\section{ACKNOWLEDGMENTS}

We acknowledge the encouragement and generous support of the Manuel D. and Rhoda Mayerson Foundation in creating the Values in Action (VIA) Institute, a nonprofit organization dedicated to the development of a scientific knowledge base of human strengths. We also thank Barabara Cherem for her assistance with recruitment as well as superintendents C. Robert Maxfield, David Aegema, and Dennis McComb; principals Henry Caudle, John Eisley, Bryan Girbach, Rande Horn, and Richard Jones; and teachers Susan Grant, Kathleen Meissner, Nancy DeWolf, Eden Collins, Donna Clark, Connie Nagle, and Lisa Evangelista for their help in conducting the study reported here. Katherine Dahlsgaard carefully edited a previous version of this paper, and Nicole Yohalem provided thoughtful suggestions.

\section{REFERENCES}

American Psychiatric Association (1994). Diagnostic and Statistical Manual of Mental Disorders (4th edn.). American Psychiatric Association, Washington, DC.

Benson, P. L., Leffert, N., Scales, P. C., and Blyth, D. A. (1998). Beyond the "Village" Rhetoric: Creating Health Communities for Children and Adolescents. Appl. Dev. Sci. 2: 138-159.

Catalano, R. F., Berglund, M. L., Ryan, J. A. M., Lonczak, H. S., and Hawkins, J. D. (1999). Positive Youth Development in the United States: Research Findings on Evaluations of Positive Youth Development Programs. U.S. Department of Health and Human Services, Washington, DC. 
Cawley, M. J., Martin, J. E., and Johnson, J. A. (2000). A virtues approach to personality. Pers. Ind. Differ. 28: 997-1013.

Crowne, D. P., and Marlowe, D. (1964). The Approval Motive: Studies in Evaluative Dependence. Wiley, New York.

Dahlsgaard, K., Peterson, C., and Seligman, M. E. P. (2001). Toward a classification of strengths and virtues: Lessons from history. Unpublished manuscript, University of Pennsylvania.

Desetta, A., and Wolin, S. (eds.) (2000). The Struggle to be Strong: True Stories by Teens About Overcoming Tough Times. Free Spirit, Minneapolis, MN.

Easterbrook, G. (2001). I'm OK, you're OK. The New Republic, March 5 , pp. 20-23.

Greenberg, M., Domitrovich, C., and Bumbarger, B. (1999). Preventing Mental Disorders in School-Age Children. Center for Mental Health Services, U.S. Department of Health and Human Services, Washington, DC.

Greenberger, E., Josselson, R., Knerr, C., and Knerr, B. (1975). The measurement and structure of psychosocial maturity. J. Youth Adolesc. 4: $127-143$.

Jahoda, M. (1958). Current Concepts of Positive Mental Health. Basic Books, New York.

Kirby, D. (1997). No Easy Answers: Research and Findings on Programs to Reduce Teen Pregnancy. National Campaign to Prevent Teen Pregnancy, Washington, DC.

Larson, R. W. (2000). Toward a psychology of positive youth development. Am. Psychol. 55: 150-183.

Leffert, N., Benson, P. L., Scales, P. C., Sharma, A. R., Drake, D. R., and Blyth, D. A. (1998). Developmental assets: Measurement and prediction of risk behaviors among adolescents. Appl. Dev. Sci. 2: 209-230.

Nathan, P. E., and Gorman, J. M. (1998). A Guide to Treatments That Work. Oxford University Press, New York.
Nisbett, R. E., and Wilson, T. D. (1977). Telling more than we can know: Verbal reports on mental processes. Psychol. Rev. 84: 231259 .

Otten, E. H. (2000). Character education (Report No. EDO-SO-2000-7). ERIC Clearinghouse for Social Studies/Social Science Education, Bloomington, IN. (ERIC Document Reproduction Service No. ED-99-CO-0016).

Peterson, C., and Seligman, M. E. P., (manuscript in preparation). The VIA Classification of Strengths. Values in Action Institute, Cincinnati, $\mathrm{OH}$.

Pittman, K. J. (1991), Promoting Youth Development: Strengthening the Role of Youth-serving and Community Organizations. U. S. Department of Agriculture Extension Services, Washington, DC.

Pittman, K. J. (2000, May 2). What youth need: Services, supports, and opportunities, the ingredients for youth. Paper presented at the White House Conference on Teenagers, Washington, DC, May 2. 2000.

Ryff, C. D., and Singer, B. (1996). Psychological well-being: Meaning, measurement, and implications for psychotherapy research. Psychother. Psychosom. 65: 14-23.

Scales, P. C., Benson, P. L., Leffert, N., and Blyth, D. A. (2000). Contributions of developmental assets to the prediction of thriving among adolescents. Appl. Dev. Sci. 4: 27-46.

Seligman, M. E. P. (1994). What You Can Change and What You Can't. Knopf, New York.

Seligman, M. E. P. (2002). Authentic Happiness. Free Press, New York.

World Health Organization (1990). International Classification of Diseases and Related Health Problems (10th Rev.). World Health Organization, Geneva.

Yearley, L. H. (1990). Mencius and Aquinas: Theories of Virtue and Conceptions of Courage. University of New York Press, Albany, NY State. 